\title{
Antikörper bleiben auch bei Älteren lern- und abwehrfähig
}

Ältere Menschen erkranken oft schwerer an COVID-19 als Jüngere, müssen häufiger intensivmedizinisch betreut werden und haben ein höheres Sterberisiko. Nach überstandener SARS-CoV-2-Infektion zeigen Ältere jedoch eine überraschend robuste Immunantwort, die sich an der Bindungsstärke ihrer Antikörper ablesen lässt.

Eine durchgemachte SARSCoV-2 Infektion bietet einen guten Schutz vor einer weiteren Erkrankung. Die vom Immunsystem gebildeten Antikörper bleiben auch Monate nach der Infektion stabil. Das haben Antikörper-Studien wie etwa jene des Instituts für Virologie der Medizinischen Universität Innsbruck in der Gemeinde Ischgl gezeigt.

) SARS-CoV-2: Die vom Immunsystem gebildeten Antikörper bleiben auch Monate nach der Infektion stabil

Lange wurde angenommen, dass die Bindungsstärke (Avidität) und damit die Abwehrkraft dieser Antikörper bei älteren Menschen weniger stark ansteigt und sie deshalb nicht so gut und nachhaltig gegen eine erneute Infektion gewappnet sind wie Jüngere. Eine im Journal of Infectious Diseases veröffentlichte Studie der Medizinischen Universität Innsbruck unter der Leitung von Prof. Dr. Reinhard Würzner (Institut für Hygiene und Medizinische Mikrobiologie) lieferte unerwartete Erkenntnisse zur Schutzfunktion der SARS-CoV-2-spezifischen Antikörper bei älteren Menschen [1].

》) Ältere Menschen, die COVID-19 überstanden haben, zeigen eine sehr gute Immunantwort

„Wir konnten zeigen, dass ältere Menschen, die COVID-19 überstanden haben, eine sehr gute Immunantwort zeigen, die mehr als ein halbes Jahr nach der Infektion deutlich gereift und nicht schlechter ist, als jene von jungen Menschen", so Würzner. Für ihre Untersuchung griffen die Forscher auf Blutproben von 217 Probanden aus der Ischgl-Kohorte zurück, die im Rahmen der ersten Antikörperstudie in Ischgl sero-positiv getestet worden waren.

\section{Alters- und geschlechts-} unabhängige Immunantwort Die nach einer Infektion gebildeten Antikörper durchlaufen einen Reifungsprozess, dessen Status mittels Aviditätsmessung bestimmt werden kann. Allgemein gilt: Je länger eine Infektion zurückliegt, desto höher ist die Avidität der Antikörper, weil B-Lymphozyten dem Erreger immer exakter angepasstere, also mit hoher Bindungsstärke ausgestattete, Antikörper bilden. Würzner: „In unserer Studie stieg die Avidität der SARS-CoV-2-spezifischen Antikörper nicht nur bei den Jüngeren, sondern überraschenderweise in fast gleichem Maße auch bei Älteren an."

Lag die Avidität ein bis sechsWochen nach Infektion in allen Altersgruppen bei durchschnittlich $18 \%$, stieg dieser
Wert sechs Monate später in allen Altersgruppen auf über $42 \%$. Auch bei Betrachtung einzelner Altersgruppen ließ sich eine altersunabhängige Steigerung festmachen.„Eine gewisse Limitation dieser Studie besteht natürlich darin, dass die untersuchten Proben von Genesenen stammen, also von Personen, die die Infektion überstanden haben", betonte Würzner.

Nachdem Daten aus zahlreichen Studien zeigen, dass Männer schwerer an COVID-19 erkranken und auch eher an der Infektion versterben, analysierten die Innsbrucker zudem, ob sich geschlechtsspezifische Unterschiede bei der Schutzkapazität der Antikörper feststellen lassen. Das Ergebnis: Die Avidität der Antikörper lag auch sieben bis acht Monate nach Infektion bei beiden Geschlechtern auf gleichem Niveau.

》) Je länger eine Infektion zurückliegt, desto höher ist die Avidität der Antikörper

Für Würzner lässt die Studie auch Rückschlüsse auf den relativ guten
Quelle: Presseaussen-

dung der Medizi-

nischen Universität

Innsbruck

\section{Die Avididtätsmessung}

Tests zur Messung der Avidität (funktionelle Affinität) von Antikörpern haben das Ziel, frische von kürzlich abgelaufenen Infektionen mit Hilfe nur einer serologischen Untersuchung trennen zu können. Dabei wird Harnsäure eingesetzt, die nur leichte, aber nicht starke, Antigen-Antikörperbindungen trennen kann. Die Avidität der spezifischen Antikörper steigt im Laufe von etwa 6 bis 12 Monaten nach einer Infektion auf ihr Maximum, und kann sogar $100 \%$ erreichen. Besonders Fälle von Infektionen mit positiven IgM-Antikörpern, die auch sensitiv frische Infektionen anzeigen, sind für eine Überprüfung im Aviditätstest prädestiniert, um durch die Unterscheidung zwischen niedriger und hoher Avidität, frische von kürzlich abgelaufenen oder latenten Infektionen trennen zu können. 
Impfschutz Älterer zu: „Ich denke, dass unsere Ergebnisse auch die Generierung funktionell guter Antikörper bei Älteren nach einer Impfung erklären. Viele Impfungen sind ja bei Älteren deutlich weniger wirksam, aber bei den COVID-19 Impfungen war dies bisher nicht besonders auffällig", so Würzner.

\section{Avidität als kostengünstiger}

\section{Ersatzmarker}

Eine Validierung der Ergebnisse erfolgte mittels Neutralisationstest, bei dem für den Nachweis neutralisierender Antikörper ein lebendes Virus eingesetzt wird. „In unserer Studie bestätigte der Neutralisationstest, dass eine hohe Avidität mit neutralisierender Antikörperkapazität, also hohem Infektionsschutz, korreliert. Damit erweist sich die Messung der Avidität als effektives und günstiges diagnostisches Mittel, mit dem es möglich wird, kostspielige Neutralisationstests zu ersetzen und den Antikörpernachweis zu optimieren", so Würzner.

Hier steht eine Anzeige.

\section{Literatur}

1. Pichler D et al (2021) Marked increase in avidity of Severe Acute Respiratory Syndrome Coronavirus-2 (SARS-CoV-2) antibodies 7-8 months after infection is not diminished in old age. Journal Infectious Diseases. https:// doi.org/10.1093/infdis/jiab300

\section{Hinweis des Verlags. Der Verlag bleibt} in Hinblick auf geografische Zuordnungen und Gebietsbezeichnungen in veröffentlichten Karten und Institutsadressen neutral.

rheuma plus $2021 \cdot 20: 148-149$ https://doi.org/10.1007/s12688021-00443-w

๑) Springer-Verlag GmbH Austria, ein Teil von Springer Nature 2021 